\title{
Quino e o mito de Narciso
}

\author{
EDUARDO PEÑUELA CAÑIZAL \\ (Professor titular da Escola de \\ Comunicaçōes e Artes da USP)
}

\section{As expansōes do sujeito}

Uma primeira leitura de Ni arte ni parte, obra de Quino que a Editorial Lumen, de Barcelona, publicou em 1981, pode me causar, digamos, a impressāo de que o conjunto de mensagens visuais ordenadas pelo conhecido cartoonista constitui, em síntese, uma espécie de comentário feito de imagens mediante o qual se fala a respeito de diferentes manifestaçōes artísticas: música, pintura, literatura, escultura, maneiras de fazer humor e modos de construir prologos. Em virtude dessas características, tal comentário imagetico, montado, observe-se de passagem, com extremo esmero, transmite, para um leitor semioticista, a idéia de que sua incrivel força comunicativa se engendra na transparência determinada pela função metalingúística, recurso fácil de surpreender em quase todas as "historietas" do livro. Assim, em sua tentativa metassemítica de interpretar a pintura - melhor dito, a chamada pintura realista -, Quino mostra, com auxilio de uma fábula muito simples como um pintor, numa esplêndida manhā de sol, realiza o milagre de, após ter representado em sua tela as duas únicas árvores da paisagem natural que lhe serviam de referente, deixar sem sombra e em perplexa solidão a pacatez de um cidadão que, sonhadoramente mansarrão, descansava ao amparo da altiva frondosidade daquelas arborreas remanescências da mata: pintada, a realidade muda de lugar e se exige, orgulhosa, na superficie de uma tela indiferente ao estado de desconcerto em que fica o her6i do bom senso ao se aperceber privado de seu objeto de valor.

Em outro de seus comentários visuais, Quino relata, com idêntica simplicidade, a fábula dos visitantes de uma exposição que, depois de se deter numa das obras, felicitam, cada um à sua maneira, o artista e se despedem com elogios em que se ressalta que sua arte possui a magia de Chagall, a poesia de Renoir, o vigor de Van Gogh, a liberdade de Picasso e a delicadeza de Modigliani. Aturdido com tamanha enxurrada de encômios à sua criatividade, o pintor, com desespero existencialista, exclama: "!Yo quería ser yo!"

Essa estória, comparada à anterior, apresenta, sem dávida, explícitas diferenças. Vista com mais vagar, porém, ela mostra que tais diferenças se definem ao nível do aparencial, já que, no atinente à narratividade, tanto o pintor existencialista quanto a personagem sanchopancesca fecham suas respectivas fábulas em estado de đisjunção. Por outro lado, 
se se exploram em pormenor alguñs traços desse enunciado narrativo em que, em termos de Propp, se define a carência, não será difícil constatar que, por meio dessa operaçāo, o narrador ancora suas criaturas de ficção numa estrutura profunda determinada pela isotopia da identidade. Somada a essa particularidade da narrativa, é de se reconhecer que, da perspectiva da modalizaçăo do fazer, os respectivos programas produzem, quando comparados, um efeito de simetrismo: o pintor assume, na primeira fábula, o papel de um sujeito operador, ao passo que, na segunda, o artista existencialista é tāo somente sujeito de um enunciado de estado. Esse simetrismo sugere, conseqüentemente, uma relação especular que não aparece, no caso, de modo expresso como, amiúde, ocorre em outros cartoons de Quino. Ao nível da narratividade, contudo, a relaçāo em jogo reitera, sutilmente, vagos lances do xadrez da identidade: de um lado, a perplexidade da personagem sanchopancesca manifesta um /saber ser/, isto é, uma curiosidade, e, de outro, a exclamação do pintor existencialista atualiza um /saber não ser/, isto $\epsilon$, uma desilusāo. Ainda desse ponto de vista, as personagens das duas fábulas se identificam mais uma vez se as encararmos a partir do esquema montado por Fontanille quando diz que:

“.. a modalização cognitiva tem a vantagem de poder servir de intermediaria entre as modalidades veridictórias e figuras passionais cognitivas como a "ignorância", a "curiosidade", a "ilusão", etc. Na medida em que as posiçōes veridictórias ("verdade" "mentira", etc.) sāo termos combinados, sua colocaçāo no quadrado é problemática, e é conseqüientemente dificil construir um sistema passional diretamente a partir da veridiç̧ão. Eis o que se obtém a partir do /saber serl, a título de sugestão:

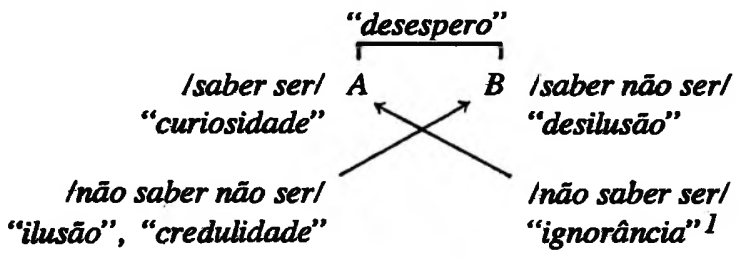

Assim sendo, o desespero se reveste das propriedades de uma figura passional complexa, o que me leva a pensar, considerando as características atribuídas às duas personagens de Quino, que os pintores das respectivas narrativas são espaços figurativos onde tal figura se manifesta em termos de perda de ilusāo ou em termos de um desejo de saber. De qualquer maneira, porém, as expressōes plásticas em que se realizam as personagens recolhem tanto os conteúdos colocados quanto os conteúdos invertidos das narrativas e com seus conflitos configuram uma especie de 
situação desesperante que, ao nível do enunciado, oscila em torno de formas conteudísticas sobredeterminadas por /saber ser/ e /saber não serf. Tais formas, no entanto, podem ser relativizadas e, nesse caso, ampliadas semanticamente como, por exemplo, Parret faz quando define a curiosidade valendo-se da combinatória /querer saber ser/ 2 . Cabe, entretanto, admitir, de antemão, que, em virtude da natureza sincrética dos cartoons, o plano do conteúdo tem, evidentemente, possibilidade de se expandir e, com isso, formar sememas em que se impliquem elementos pragmáticos, cognitivos e tímicos.

Diante dessas particularidades e pensando nas formas narrativas e discursivas como extremos do trecho do itinerário em que, segundo a teoria greimasiana, se efetuam os percursos de sentido, quero antecipar que dos fenômenos expansionais por que passam, durante os atos de leitura, os conteúdos de qualquer manifestaçảo simb6lica - no caso, os cartoons de Quino - me interessam, nesta ocasiäo, somente aqueles que mantêm conexão com aspectos das transformaçōes tímicas e cognitivas, 0 que me permite trabalhar com a idéia de que, ao definirem forçosamente programas narrativos, essas transformaçōes foram sobredeterminadas por objetos de valor participativos, isto $\epsilon$, por objetos cuja principal propriedade advém da realização de revelaçöes de conjunçảo em que, no mínimo, intervêm, simultaneamente, dois sujeitos. Tal posicionamento se deve, como pretendo demonstrar neste trabalho, a dois fatores fundamentais: de um lado, a isotopia do narcisismo, encarada, principalmente, como um modelo que me permita estabelecer um corpus representativo da obra de Quino e, de outro, a configuraçäo da identidade que, mesmo sendo um conjunto de significaçōes virtuais, se torna, nas criaçōes do autor de Mafalda, uma espécie de invariável cuja presença, em virtude de possuir um alto teor poético, sobredetermina a ambigüidade dos percursos figurativos em que se localizam os traços responsáveis pelo inconfundivel estilo do cartoonista argentino. ${ }^{3}$

\section{A contração dos objetos}

Ao falar do sentido e da tarefa do semioticista, Greimas, em Du Sens, esclarece, em nota, o que, nessa oportunidade, ele entende por isotopia:

Por isotopia, entende-se geralmente um feixe de categorias semanticas redundantes, subjacentes ao discurso considerado. Dois discursos podem ser isotópicos mas nāo isomorfos." 4

Rastier, em Le developpement du concept d'isotopie ${ }^{5}$, considera esse entendimento genérico ao ponto de que ele permite afirmar, por exemplo, que todos os enunciados de uma língua que coloquem em jogo a categoria do número seriam, nesse sentido, isotópicos. Tal assertiva transforma a definiçāo greimasiana em algo inútil ou quase inútil e, mesmo sem considerar a importáncia dos processos subjacentes, Rastier parte para a segunda definição de isotopia, citando, para tanto, a seguinte passagem da Sémantique Structurale: 


\section{"Uma mensagem ou uma seqüência quais- quer do discurso somente podem ser conside- radas como isotopia se elas possuem um ou vários classemas em comum."6}

Essa segunda definiçāo, sem dúvida, apresenta, em certa medida, maior grau de precisão, embora tenhamos de admitir, com base na formula $\left(\mathrm{Sq}=/ \mathrm{N}_{1}+\mathrm{Cs}_{1} /+/ \mathrm{N}_{2}+\mathrm{Cs}_{1} /\right)$, que ela também possui imprecisōes. Assim, ao comentar a frase le chien aboie, Rastier, para mostrar a isotopia, diz que "o classema /animal/" se repete em chien e aboie, o que catacteriza a manifestação da isotopia. Mas esse entendimento, a meu ver, termina sendo inconveniente e estreito se nāo o relacionamos com os conceitos que Greimas exprime na segunda frase da primeira definiçāo. Isto $\hat{\epsilon}$, creio que para que a isotopia se configure devemos ter, certamente, a repetição de um mesmo classema, mas tal repetição produz sentido unicamente quando as frases ou os textos não forem isomorfos. Quero deixar claro, por conseguinte, que a isotopia de le chien aboie nāo me interessa pelo simples fato de que ela se realiza num espaço semiótico isomórfico ao nível da frase, o que faz com que a explicação de Rastier se impregne de certa obviedade tautológica. Por isso, já que não desejo me deter nessa controvérsia, a isotopia que me servirá de modelo $€$ a que se engendra na redundância de classemas subjacente ao desespero cuja repetição, nas duas estórias que venho comentando, leva a efeito o conflito de sentido sobredeterminado por /curiosidade/ e /desilusão/.

Com base, pois, nesse modelo isotópico não me parece difícil montar um corpus que me permita descortinar alguns dos traços mais relevantes das inconfundíveis criações de Quino e entrever algo da trágica condição humana que se oculta nas máscaras do riso. E para que o leitor firme a idéia de que o desespero, entendido como uma perda definitiva da esperança, inscreve o humor do famoso cartoonista no âmbito do patético, é suficiente, acredito, transcrever a apocalíptica e derradeira cena da Foto 1 (no final do artigo).

Tenho para mim, porém, que as redundâncias subjacentes a que se refere Greimas podem, com certeza, servir para aperfeiçoar o modelo de isotopia e, conseqüentemente, fazer que de sua aplicação resulte, para benefício deste trabalho, um corpus mais reduzido e funcional. Vale dizer, por conseguinte, que o corpus não será estabelecido a partir de substâncias semânticas cognitivas ou tímicas, já que a isotopia somente é observável no espaço semântico constituído pelas formas do conteúdo ou seja, no espaço semântico construído por combinatórias sememáticas diferentes em que a redundância se faz presente pela repetição de um sema ou classema que confere a cada uma das combinatórias um traço comum -.

Em Sémiologie Psychoanalytique, María Carmen Gear e Ernesto César Liendo, ao estudar os fenômenos de repetição em situaçōes terapêuticas, mostram como os relacionamentos seguem, com freqüência, moldes tipicamente narcisísticos: analistas e pacientes compartilham um imaginário simetrismo especular e, quando menos se espera, a narrativa que ambos vão construindo emerge desse jogo de espelhos onde os rostos 
dos protagonistas, coadjuvados pelos fantasmas da psicose, se confundem e se emaranham em programas narrativos cujos objetos de valor são, no geral, autênticas crises de identidade. As perturbaçōes do paciente são recebidas com certa passividade pelo analista e, com base nessa impressão, o próprio paciente contribui inconscientemente para criar uma atmosfera psicótica que, errática, invade os palcos da linguagem e envolve os sujeitos dessa encenação numa nebulosa diluição da identidade que faz com que o inconsciente domine, por completo, boa parte das cenas:
"É clássico dizer que na psicose, o incons- ciente está na superficie, $\dot{E}$ consciente. $\dot{E}$ mesmo por isso que näo me parece que tenha grande importancia o fato de que ele seja ar- ticulado. Nessa perspectiva, bastante instruti- va em si mesma, nós podemos de início notar que não é puramente e simplesmente, como Freud sempre sublinhou, por esse traço ne- gativo de ser um Unbewusst, um não-cons- ciente, que o inconsciente tem sua eficácia. Traduzindo Freud nós dizemos - o incons- ciente, é uma linguagem. Que ele seja arti- culado, não implica portanto que ele seja re- conhecido. A prova é que tudo se passa co- mo se Freud traduzisse um língua estrangei- $\mathrm{ra}$, e mesmo a reconstituisse por decupagem. $O$ sujeito está simplesmente, no que respeita d̀ sua linguagem, na mesma relaçāo que Freud. Partindo da idéia de que alguém pudesse fa- lar uma língua que ignore totalmente, nós di- rímos que o sujeito psicótico ignora a língua que fala." 7

Tal sucede, por exemplo, na situação plasticamente encenada pelo gênio de Quino que vemos na Foto 2 (no final do artigo). Aí a crise de identidade se torna visivel e os gestos da repetição produzem condiçōes significantes excelentes para que se manifeste o tipo de isotopia que realmente me interessa: trata-se da formação de conteúdos em que se integram em sememas comprometidos com a subjetividade ou com classemas subjacentes a mensagem dessa linguagem inconsciente que a personagem do cartoon reproduzido, enquanto sujeito semiótico de um enunciado narrativo, não sabe traduzir.

À vista do exposto, julgo legítimo contar com a premissa de que a repetição de sememas formalizadores do conteúdo de desespero reitera, em vários cartoons de Quino, um classema subjacente ao subconjunto de semas conotativos de cuja seleção depende o tipo de combinatória em que se manifesta a crise de identidade. No quadro dessa hip6tese creio não ser dificil trabalhar com o pressuposto de que, em termos de conotação, a isotopia que será utilizada para a demarcação do corpus tem suporte em processos de analogia, isto $\epsilon$, em arranjos de sememas que remetem a significados especulares. Dessa perspectiva, parece pertinente 
orientar a leitura dos cartoons para aquelas áreas das mensagens plásticas em que

\begin{abstract}
"a iconicidade em si será finalmente definida como a produçāo de um efeito de sentido de realidade, caracteristico náo de tal linguagem ou de tal signo mas de um certo tipo de discurso que explora as conotaçöes sociais $e$, entre outras, o que tal sociedade pensa de suas diferentes linguagens quanto a suas relaçōes respectivas à realidade."8
\end{abstract}

Para tal fím me é necessário, por conseguinte, lidar com mecanismos de categorização plástica que permitam, com certo grau de rigor, assinalar as áreas das mensagens em que a especularidade se explicita ou se implicita e, nesse particular, o corpus será constitúdo, principalmente, de imagens em que a especularidade explícita é uma constante. Mas, por outro lado, a isotopia da especularidade se reporta a um conterido em que a problemática do sujeito e da identidade sempre estarão em jogo e, nesse sentido, o corpus se reduzirá ainda mais, fazendo-se mais preciso na iconicidade cujo efeito de sentido provém não da realidade exterior, natural ou objetivamente fabricada, mas da realidade interior em que se localizam os reinos do inconsciente.

Em "Remarques sur la fonction du langage dans la découverte freudienne", capítulo VII de Problèmes de Linguistique Générale, Benveniste, argutamente, observa que $o$ analista

"opera sobre aquilo que o sujeito lhe diz. Ele se considera no discurso que aquele the apresenta, ele o examina em seu comportamento locutório, "fabulador", e através desses discursos se configura lentamente para ele um outro discurso que ele se encarregara de explicitar, o do complexo oculto no inconsciente. Da mise au jour desse complexo depende o sucesso da cura, que testemunha por sua vez que a indução era correta. Assim do paciente ao analista $e$ do analista ao paciente, o processo inteiro se opera pelo porta-voz da linguagem."

O que mais me impressiona dessa passagem é a lucidez com que o conhecido lingüista penetra num dos pontos relevantes e atuais da teoria de Freud. Mas, no atinente à cura, confesso que meu interesse é muito frágil, pois, a esse respeito, não gostaria de cair na armadilha doloridamente condenada por Antônio Machado quando constata que

"En el corazón tenía

la espina de una pasión;

logré arrancármela un día;

ya no siento el corazón." 
Talvez em virtude disso, desejo reler o fragmento de Benveniste procurando me desviar das trilhas por onde, tranqüila, costuma caminhar a ingênua clarividência. Prefiro vagar nas entrelinhas carregando sempre a expectativa de quem vive com a idéia fixa de se encontrar com os fantasmas da significância ou do sentido obtuso, como queria Roland Barthes. Ao proceder dessa maneira, sinto que as palavras de Benveniste me envolvem numa espécie de labirinto feito de espelhos - imaginários espelhos - e, de repente, sem saber exatamente o porquê, tenho a sensação única de quem convive com a certeza de que as imagens do "complexo oculto no inconsciente" se refletem, com mais ou menos nitidez, nesse outro sintagma em que se declara que "o processo inteiro se opera pelo porta-voz da linguagem". Fico, enfim, seduzido pela visão de que essa primeira frase $\epsilon$ a imagem que ganha fantasmagórica corporalidade atraves do "porta-voz da linguagem" $e$, ao atingir esse estado, me apercebo para entrar,com plenitude, nos domínios da significação que se vislumbram nas entrelinhas. Não creio, contudo, que tal atitude seja fruto de um excesso de fantasia ou de uma falsa alucinação. Acredito firmemente na minha intuição e acaricio a certeza de que na questāo da ordem simbólica, como reconhece Américo Vallejo 10, está presente uma questão relativa ao ser do sujeito, uma espécie de carência constitutiva que, enquanto fenômeno do inconsciente, deixa marcas na enunciação e nos enunciados por onde circula o desespero do pintor existencialista do pacato cidadāo sanchopancesco e, evidentemente, do atlético operário que, colérico e aturdido, não rompe sua aparente identidade no espelho porque o espelho não the devolve a imagem que ele, depois desses rodeios, possa estraçalhar.

Em suma, quero crer que, depois desses rodeios, possa, finalmente, apontar o traço responsável pela homogeneidade do corpus por mim estabelecido: trata-se de cartoons em que o espelho, de um lado, irradia efeitos de realidade aparencial produzidos pela iconicidade que faz deles objetos facilmente reconhecíveis e habituais, e, de outro, exibe processos de ruptura onde se localizam marcas da enunciaçāo que a teoria semi6tica, em nome de paran6icas imanências, não quis, no geral, analisar.11

\section{As realizaçōes do imaginário}

A enunciação converte a língua em discurso ou, em outras palavras, a enunciação, enquanto operação semiótica, sobredetermina um sujeito $\mathrm{e}$, conseqüentemente, traz à baila os enigmáticos sintomas da identidade camuflados no que Benveniste denominou instâncias discursivas. Nelas e mediante um constante jogo de contrastes, os indícios da identidade se escondem, assim como, desdenhada por Narciso, se escondeu, vergonhosa desse desprezo, a ninfa Eco, sutilmente sugerida nesta passagem de "De la subjectivité dans le langage":

"A consciência de si só é possivel se ela se prova por contraste. Eu somente emprego eu me dirigindo a alguém, que será em minha 
alocução um tu. É esta condição de diálogo que $E$ constitutiva da pessoa, porque ela implica em reciprocidade que eu me torne tu na alocução daquele que por sua vez se designa por eu. É aí que nós vemos um princípio cujas conseqüências devem ser desenvolvidas em todas as direçōes. A linguagem só é posstvel porque cada locutor se coloca como sujeito, devolvendo a si próprio como eu em seu discurso. Desse fato, eu postula uma outra pessoa, aquela que, sendo exterior a "mim", torna-se meu eco ao qual eu digo tu $e$ que me diz tu. A polaridade das pessoas, tal é na linguagem a condição fundamental, em que o processo de comunicação, do qual nós partimos, não é senão uma conseqüência pragmática. Polaridade aliás muito singular em si, e que apresenta um tipo de oposição de que não encontramos em nenhuma parte, fora da linguagem, equivalente. Essa polaridade não significa igualdade nem simetria: " $e$ go" tem sempre uma posiçāo de transcendência relativamente a tu; entretanto, nenhum dos dois termos se concebe sem o outro; eles são complementares, mas segundo uma oposiçāo "interior/exterior", e ao mesmo tempo eles são reversiveis. Procure-se um paralelo: não se encontrará. Única é a condiçāo do homem na linguagem." 12

Quero crer, por conseguinte, que a relação eu: tu não soluciona o problema da subjetividade: ela funciona, falando metaforicamente, como se fosse a entrada dos rochedos cavernosos em que a ninfa das águas se abrigou à espera de alguém que a chamasse, à espera, portanto, de uma voz que ela, do fundo do seu esconderijo, repetiria, distante, imitando, com sua resposta, a imagem sinestética do narcisismo. Agindo dessa maneira, Eco provava o que muitos e muitos séculos depois intúa Freud ao dizer que, em essência, "uma palavra é, em última análise, o resíduo mnêmico de uma palavra que foì ouvida." 13 Nesse aspecto, não há como negar a perspicácia e 0 alcance das intuiçóes de Benveniste, embora seja de se admitir, por outro lado, que, em nome de uma semiótica geral, a grande maioria dos semioticistas que estudaram os processos de enunciaçāo tenha caído na armadilha de se encantar, ingênuos, com o eco das palavras como se ele fosse a "realidade" De modo que, nesse quadro de valências, a relação eu:tu, enquanto máscara do sujeito e da sua identidade, foi utilizada, principalmente, para formular questōes cuja solução nunca ultrapassou as fronteiras impostas pelo imperialismo do referente, já que, a partir de um entendimento relativamente estreito de alguns conceitos de Benveniste, os semioticistas da enunciação vincularam o chamado "appareil formel du discours" ao aqui e ao agora de uma dimen- 
são espaço-temporal pertencente, segundo eles, ao sujeito da enunciação. Essa paradoxal atitude me levou a pensar que a dualidade eu:tu, quando vista em termos de um aqui-agora determinados única e exclusivamente pela exterioridade, constitui, na verdade, o plano da expressão de um sistema de relaçōes cujos valores de semiose ficam sem definição, ao que tudo indica, pelo simples fato de que da oposição exterior/interior é considerada tão somente um elemento. Dessa perspectiva teórica, pois, da expressão da subjetividade faria parte o eco da identidade, razão pela qual a relaçāo eu:tu seria, em termos freudianos, apenas uma representação de palavra desvinculada, ao que tudo indica, da representação de coisa.

Tenho para mim, diante do exposto, que uma leitura pautada por esses princípios empobrece o trabalho interpretativo do enunciatário. Tal se poderá constatar, por exemplo, se aplicarmos ao cartoon de Quino reproduzido na Foto 3 (no final do artigo) o modelo referencial da enunciação formulado desta maneira por Jean-Pierre Desclés:

\begin{abstract}
"Os enunciados declarativos têm por valor referencial situaçōes. Certas situaçōes são estaticas, ou, mais propriamente, estativas, outras sāo dinâmicas. As primeiras permanecem estáveis durante um certo intervalo temporal onde nem começo nem fim são contemplados. Por exemplo o enunciado:
\end{abstract}

(1) João está em Paris

admite uma proposiçāo subjacente:

(1') "João estar-em Paris"

que é verdadeira sobre um intervalo temporal aberto ]e, $d[$ :

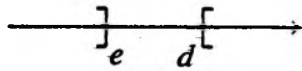

Em cada instante do intervalo $]$ e, $d[$, o valor de $(I$ ') é "o verdadeiro"

Sob o nome de proposição, nós entendemos aqui designar uma expressão constituida por operaçōes de predicaçāo; ela tem por valor lógico ora "o-verdadeiro", ora "o-falso" Um enunciado é então uma expressão lingüística constituida por dois tipos de operaçōes: as operaçōes de predicação e as operaçōes de enunciação. A enunciação contribui para fixar as coordenadas referenciais da proposiçāo subjacente ao enunciado, quer dizer, para determinar a posição da proposição no espaço referencial do enunciador." 14

Em primeiro lugar, se a enunciação contribui para fixar as coordenadas da proposiçāo subjacente ao enunciado, o cartoon acima reproduzido coloca em questāo, numa leitura baseada na isotopia narcisista, as 
coordenadas referenciais de Desclès: assim, uma das proposiçōes subjacentes ao enunciado poderia ser, usando os conceitos desse autor, 2 senhores-sentar-à-mesa e 1 garçom-estar-em-pé em-bar-diantedum-espelho. No caso, a operação de enunciação conduz a um resultado dilemático devido ao fato de que, basicamente, a referencialização da proposição ou proposições em questāo, a valorizar tão somente um espaço relativo à exterioridade do enunciador, projeta, no espaço semí́tico propriamente dito, marcas que contradizem os valores da dimensāo ambiental ou exterior: no espelho não se reflete a imagem de uma das personagens, fenômeno que, de modo explícito, contraria os princípios da realidade situacional representada pelo sujeito enunciador. Mesmo que, na condiçăo de enunciatário dessa mensagem, eu tentasse analisar o plano do conteúdo seguindo o modelo de enunciação enunciada de Manar Hammad, seria

\section{"a distinção /enunciação/ vs /enuncia- do/ provém do plano do conteúdo, e ela é in- diferente a sua expressão." 15}

Prefiro, no que diz respeito ao trabalho desse autor, ficar com as idéias que me sugere o que ele chama de l'effet de miroir du discours, pois, nelas, encontro elementos metalingüisticos capazes de me auxiliar, de maneira decisiva, na compreensāo do importante papel que desempenha o mito de Narciso - especialmente o narcisismo primário a que se refere Freud em seu estudo Uma introduçāo ao narcisismo - no cartoon de Quino.

O chapéu no cabide, a inclinaçăo do garçom, a acentuada gestualidade da personagem que faz o pedido, o maço de cigarros sobre a mesa, enfim, os componentes da cena refletidos no espelho e a ausência da personagem de paletó preto na superficie desse mesmo espelho constituem, mesmo em conjunto, um "effet de miroir du discours", mas, no caso, um efeito que produz uma espécie de configuração alucinatória cujo conteúdo se relaciona, em certa medida, com o sentido procurado por Lacan em "Le point de capiton" quando diz:

"O sujeito escuta com seu ouvido alguma
coisa, mas o que ele escuta existe ou não
existe? É evidente que não existe, e que por
conseqüência, é da ordem da alucinaçāo,
vale dizer de uma percepção falsa. Isso é su-
ficiente?" 16

Creio que o cartoon de Quino responde negativamente à pergunta lacaniana, embora o que me interessa não é precisamente a denotação da resposta: o que me intriga $e$ o fato de que, mesmo sendo fruto de uma percepção falsa, a alucinação nasce de uma percepção. Ela se faz presente na representaçäo plástica da cena do restaurante quando percebo que a imagem da personagem do palet 6 preto se ausenta da superfície do espelho: acredito, pois, que se noto a ausência é porque a percebo e essa percepção nāo é, exatamente, uma percepção verdadeira. Por outro lado, assim como o sujeito que escuta pode escutar algo que não 
existe - o eco, por exemplo, não me prova a existência da ninfa das águas -, o sujeito que vê pode, por sua vez, ver algo que não existe ou que não está lá. A esse respeito é significativo constatar que o próprio Lacan afirme que
"O olhar não se situa simplesmente ao nivel dos olhos. Os olhos podem muito bem não aparecer, ser mascarados. O olhar não é o rosto de nosso semelhante, antes porém, a ja- nela da qual nós supomos que ele nos espia. É um $\mathrm{x}$, um objeto diante do qual o sujeito se torna objeto." 17

Talvez a ausência da imagem refletida no espelho seja, na arquitetura da mensagem plástica, a abertura que deixa passagem para o lugar de onde o autêntico sujeito da enunciação espreita e, sendo assim, a percepção referida somente $\epsilon$ falsa no que diz respeito aos referentes que integram o universo da exterioridade, já que, em termos de uma referencialidade pertencente à topologia do inconsciente, essa mesma percepção encontre razão de existência em perceptos que não são fixados pelos poderes da consciência. Nessa hipótese, o effet de miroirdos cartoons de Quino mereçam uma leitura que arme o tear com que o enunciatário entrelace contextos formadores das configuraçōes da identidade.

No desenho da Foto 4 (no final do artigo) E possível observar esse effet de miroir em que a subjetividade se oferece ao leitor através das rupturas especulares: nem sempre o espelho reflete a "realidade" que the foi colocada na frente e nem sempre a "realidade" que lhe foi colocada na frente ocupa, na superficie do espelho, o lugar que os chamados fenômenos de 6 tica lhe determinam. Ocorre com essa realidade algo semelhante ao que Lacan assinala ao dizer que quando

"você vê um arco-fris, vê alguma coisa inteiramente subjetiva. Você o vê a uma certa distância, atravessando sobre a paisagem. Ele não está lá. É um fenômeno subjetivo. $E$ no entanto, graças a um aparelho fotográfi$c o$, você o registra sem dúvida objetivamente. Então, o que é isso? Nós não sabemos mais muito bem - não é? - onde está o subjetivo, onde está o objetivo. Ou então não seria que nós temos o hábito de fazer em nosso curto entendimento uma distinção muito sumária entre o objetivo e o subjetivo? $O$ aparelho fotografico, um aparelho subjetivo, inteiramente construido com o auxilio de um $\mathrm{x} e$ de um $\mathrm{y}$ que habitam $o$ dominio onde vive o sujeito, quer dizer, aquele da linguagem?" 18

Parece, pois, que as idéias de Lacan não vâo de encontro ao pensamento de Benveniste sobre a linguagem e a subjetividade. Nesse parcular, creio que, no cartoon em questāo, o effet de miroir estrutura, 
com esse jogo de indefiniçōes e rupturas, o percurso de uma configuração discursiva relacionada com a complexa problemática da identificaçāo. Assim temos, em termos metalingǘsticos, o seguinte esquema orientador da leitura:

-Configuração discursiva

["identificaçāo"]

- Definida como

- Percurso figurativo

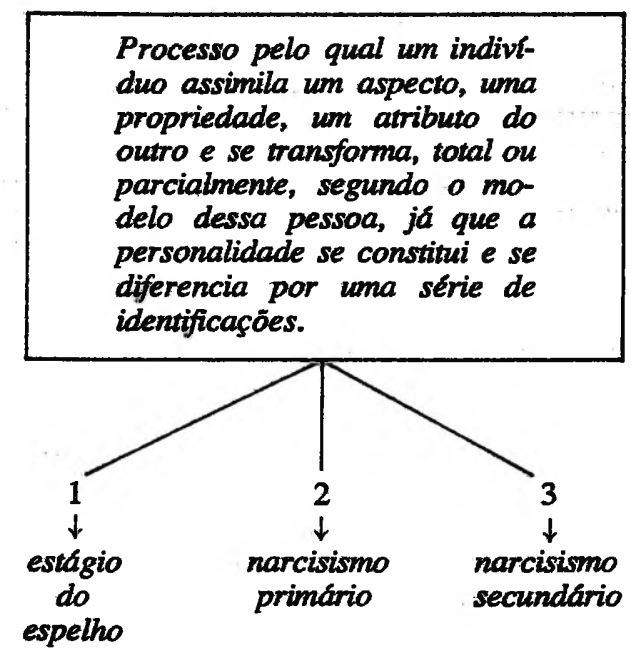

A identificação, enquanto aspecto virtual, permite que sejam realizadas tantas leituras quantos forem os percursos figurativos levantados. No que diz respeito ao corpus deste trabalho, $\epsilon$ evidente que poderiam ser levantados muitos outros percursos figurativos, devido à opacidade poética da obra de Quino. Mas, sendo minha intenção me deter tão somente em percursos que atualizem particularidades semíticas relacionadas com o narcisismo, a tarefa de leitura ficara, evidentemente, reduzida, limitada mesmo às marcas da enunciação e à maneira como elas se deixam perceber em textos plassticos. Cabe advertir, no entanto, que as marcas que aqui me interessam fazem parte da interioridade, isto $\hat{E}$, da subjetividade que se implica no que Lacan entende por sujeito barrado (\$). Justifico essa minha opçāo porque julgo que o narcisismo primário, tal qual pensado por Freud e estudado por Green e Lacan, se vincula a esse tipo de subjetividade. Quanto ao percurso do narcisismo secundário, minha proposta de leitura nāo lhe dará tanta atenção, já que ele, ao que tudo indica, constitui um iconismo de fácil percepção.

Ao situar a figura formada pela ausência da imagem refletida no espelho no percurso figurativo do narcisismo primário, tenho para mim que essa figura emparenta, no atinente ao significado, com algumas das idéias de que se vale Freud para definir o chiste, como, por exemplo se constata nesta passagem: 


\begin{abstract}
"O chiste comporta no mais alto grau o carâter de uma "idéia súbita" involuntária. lgnora-se o instante que precede o traço cômico que se vai disparar e que não se necessitará revestir de palavras. Experimenta-se antes alguma coisa indefinivel, que se assemelharia a uma auséncia, a uma supressão súbita da tensäo intelectual, depois de repente o chiste surge, quase sempre paramentado das palavras que o revestem." 19
\end{abstract}

Não $\epsilon$ outra a impressão que fica quando notamos a ruptura que se estabelece entre o espelho e a personagem do paletó preto. Esse arranjo ou combinatória plástica faz rir, como faz rir um chiste. Mas, quando cessa o riso, percebemos que tanto na gestualidade da personagem quanto na ausência de sua imagem no espelho o cartoon expressa algo indefinivel: de um lado, a perda súbita da tensâo intelectual conota, ao nivel da enunciação e do enunciado, a presença de algo inconsciente que projeta marcas na enunciaçāo e se representa nas personagens, e, outro, o caráter involuntário de o chiste que se configura na cena denuncia a invisibilidade presente do sujeito barrado, isto $\varepsilon$, Quino traz ao espaço material da expressão a dimensāo imaginária do narcisismo primário. Não se trata, portanto, de representar, considerando a oposição exterior/interior, o que a semiótica, em geral, admite como referente. Trata-se de representar, isso sim, a subjetividade tal como definida por Lacan e, em parte, por Benveniste. Ou, para ser mais preciso, o que minha interpretação quer mostrar 6 que, nesse desenho e nos outros do corpus, aparece representada plasticamente a barra que a relaçāo imaginária estabelece entre o sujeito (S) e o Outro (Autre) neste conhecido esquema lacaniano.

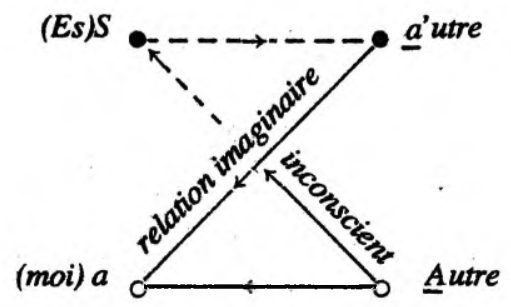

\title{
Aí temos a interrupção
}

"da fala plena entre o sujeito e o Outro, e seu desvio pelos dois mim, a $e$ a', e suas relaçōes imaginárias. Uma triplicidade é aqui indicada no âmbito do sujeito, que recobre o fato de que é o mim do sujeito que fala normalmente a um outro, e do sujeito, sujeito $S, e m$ 
terceira pessoa. Aristóteles fazia notar que não se deve dizer que o homem pensa, mas que ele pensa com sua alma. Assin também, eu digo que o sujeito se fala com seu mim."20

Enfim, parece-me que o percurso figurativo do narcisismo primário abre possibilidades de leitura que não existem nesse jogo alucinatório que, em nome da pertinência semiótica, foi armado por alguns seguidores da teoria greimasiana aplicada à manifestaçōes visuais. No caso dos cartoons de Quino que integram o corpus deste trabalho, a ruptura que 0 cartoonista cria ao quebrar o prinćpio de correspondência entre imagens referenciais e imagens especulares serve para provar que, mesmo parecendo paradoxal, as marcas da enunciação não se explicam tão somente a partir da relação com o aqui e o agora do enunciador: é necessário, se queremos penetrar em camadas mais fundas da significaçāo, reconhecer que $o$ inconsciente faz parte, também, do universo referencial. Dessa maneira, as configuraçōes da identificaçāo e a imensa riqueza de seus percursos figurativos na arte de todos os tempos e lugares descortina novos horizontes para as análises semíticas.

É mister, por conseqüéncia, trazer ao campo das práticas de leitura instrumentos teóricos que se engendrem num entendimento mais amplo dos processos de produção e recepção dos textos artísticos. Trazer, como fez Luc Régis em seu excelente ensaio Le scarafié et le tatoué. Approche d'un système semi-symbolique (Documents, VII, 64, 1985), novas formas de homologação que auxiliem, de maneira original, nos exercícios de leitura. Por isso, e sem maiores pretensōes, desejo finalizar este trabalho apresentando, com base no já exposto e tomando como texto objeto o desenho da Foto 5 (no final do artigo), uma, a meu ver, sugestiva forma de homologaçăo. Para tanto, parto da idéia de que, nesse texto visual, o dilema da identificação, além de se tornar mais dramático em função de uma visão descontínua do presente, desencadeia, com a ruptura ditada pela não coincidência de imagens e momentos referências com imagens e ações refletidas no espelho, um processo de regressão mediante o qual a subjetividade passa a fazer parte do espaço semítico. Outra vez, pois, o sujeito barrado (\$) E representado por esse tipo de rompimento, o que me permite estabelecer a invariável desta homologação:

Ia identidade das imagens refletidas com as imagens referenciais externas/

"Narcisismo secundário" la nāo correspondência

de imagens por causa da ruptural

Tal princípio, em suma, orienta uma leitura sistemática de boa parte da obra do famoso artista argentino. É só navegar com ele para viver a grande aventura de que a gente, enquanto enunciatário e sujeito da leitura, sonha estar singrando o mare nostrum da subjetividade. 
1 Fontanille, J.: Le Desespoir, Documents, $\mathrm{n}^{\circ} \mathrm{16}, 1980$, p.21.

2 Cf. Parret, H.: Eléments pour une typologie raisonné des passions, Documents, IV, 37, 1982.

3 Nāo faz parte deste trabalbo, por razōes de compreensāo, um estudo pormenorizado das formas narrativas e discursivas dos cartoons.

4 Greimas, A.J.: Du Sens. Éssair Semiotiques, Paris, Seuil, 1970, p.10.

5 Cf. Rastier, F.: Le développement du concept d' isotopie, Documents-, III, 29, 1981, p.6/9.

6 Greimas, AJ.: Stmantique Structurale, Paris, Larousse, 1966, p.53.

7 Lacan, J.: Le SEminaire (Livre III - Les Psychoses), Paris, Seuil, 1981, p.20.

8 Floch, J-M.: Petites Mythologies de l oeil et de l esprit. Pour une Sémiotique Plastique, Editions Hades-Benjamins, Amsterdam, 1985, p.12.

9 Benveniste, E.: Problemes de linguistique générale, Paris, Gallimard 1966, p. $75 / 76$.

10 Cf. Vallejo, A. e Magalhāes, L.C.: Lacan: Operadores de Leitura, Såo Paulo, Perspectiva, p.78.

11 Utilizo, para a constituiçăo do corpus, somente os seguintes livros de Quino: Déjerme Inventar, Yo que usted..., Mundo Quino, NiArte Ni Parte, Gente en su sitio e Bien, Gracias Y Usted?

12 Benveniste, E.: op. cit., p.260.

13 Frend, S.: $O$ Ego e old (e outros trabalhos), O.C., v. XIX, Rio de Janeiro, Imago Editora, 1976, p.34.

14 Desclés, J-P.: Représentation des Connaissances, Documents, VII, 69, 1985, p.5.

15 Hammad, M.: "L'énonciation: Procès et Systeme", in Langages, ñ 70 1983, p.45.

16 Lacan, J.: op. cit., p.293.

17 Lacan, J.: Le Séminaire (Livre I: Les Écrits techniques de Freud), Paris, Seuil, 1975, p. 245.

18 Idem, p. 91.

19 Frend, S.: Le mot d' esprit et ses rapports avec l' inconscient, Paris, Gallimard, p. 278.

20 Lacan, J.: Le Seminaire (Livre III: Les Psychoses), op. cit., p.23.

As reproduçóes fotograficas dos desenhos de Quino foram feitas por Eduardo Peuีuela $e$ as traduçōes dos originais franceses sāo da responsabilidade de Paulo Eduardo Lopes.

RESUMEN

El presente trabajo se vale de un modelo isotópico inspirado en la teoría greimasiana para establecer un corpus que se compone de varios cartoons de Quino. El anflisis de ese corpus tiene como principal objetivo la elaboración de un itinerario de lectura que nos pueda revelar que las marcas de la enunciación no son sencillamente signos del narcisismo secundario, sino, esencialmente en los mensajes especulares, vestigios de algo que, en la teoría freudiana, se relaciona con los procesos del narcisismo primario. 
As fotos reproduzidas nesta página e na seguinte foram tiradas de:

Quino. 1983. Déjenme inventar. Barcelona, Editorial Lumen

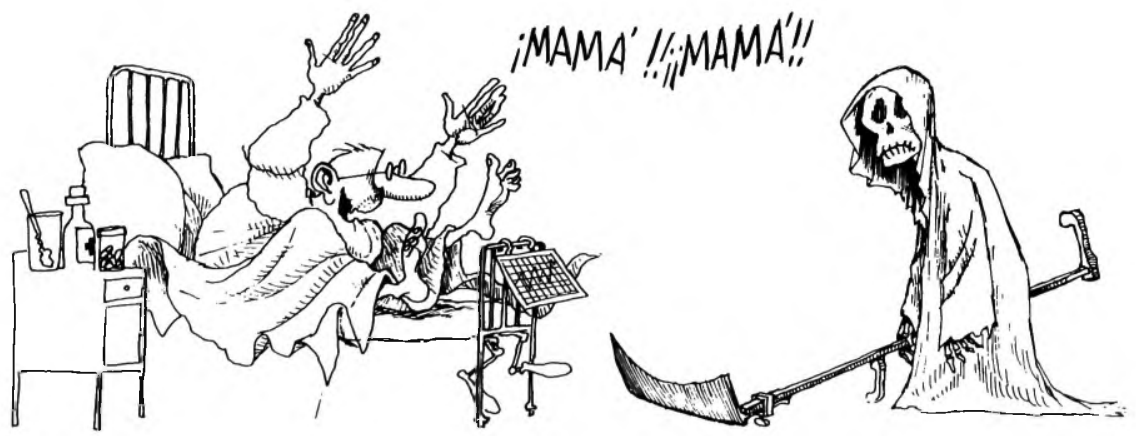

FOTO 1

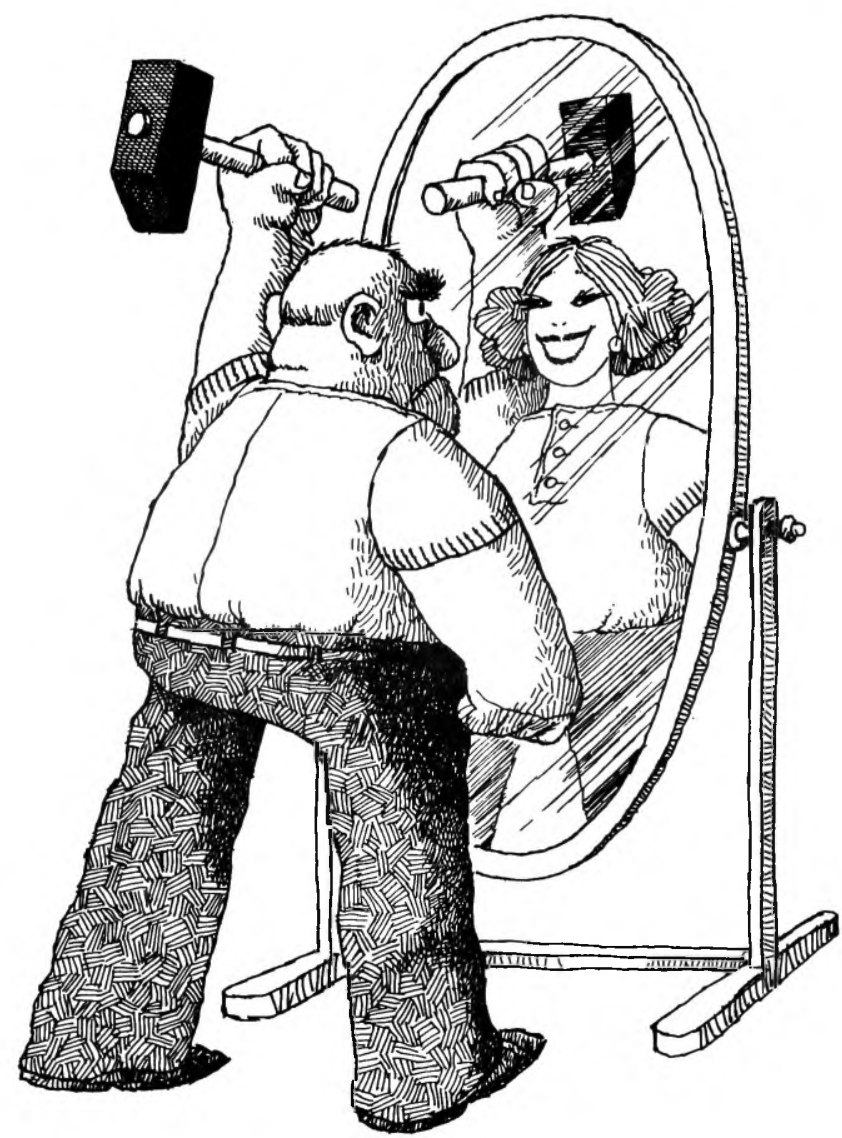

FOTO 2 


\section{FOTO 3}
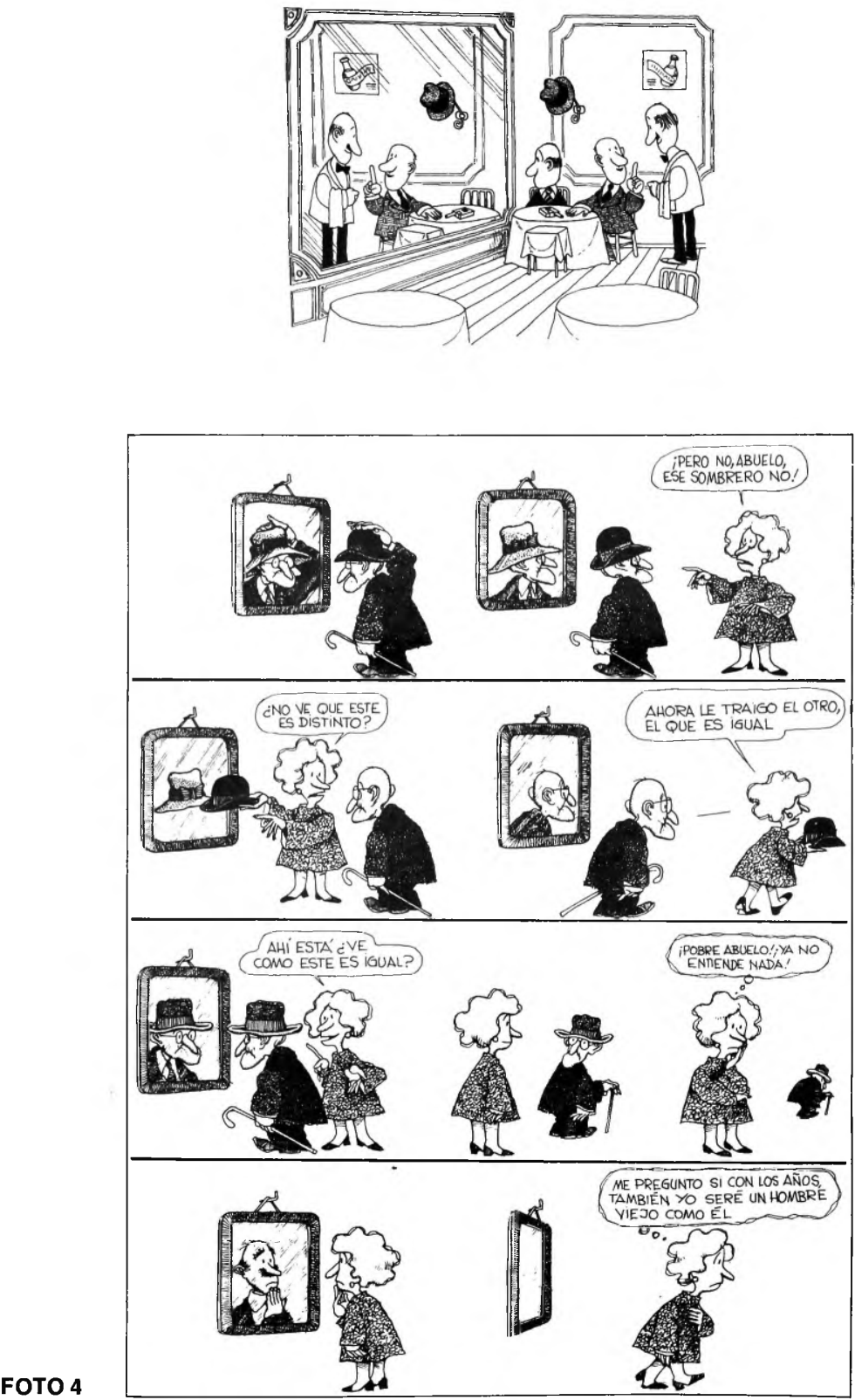


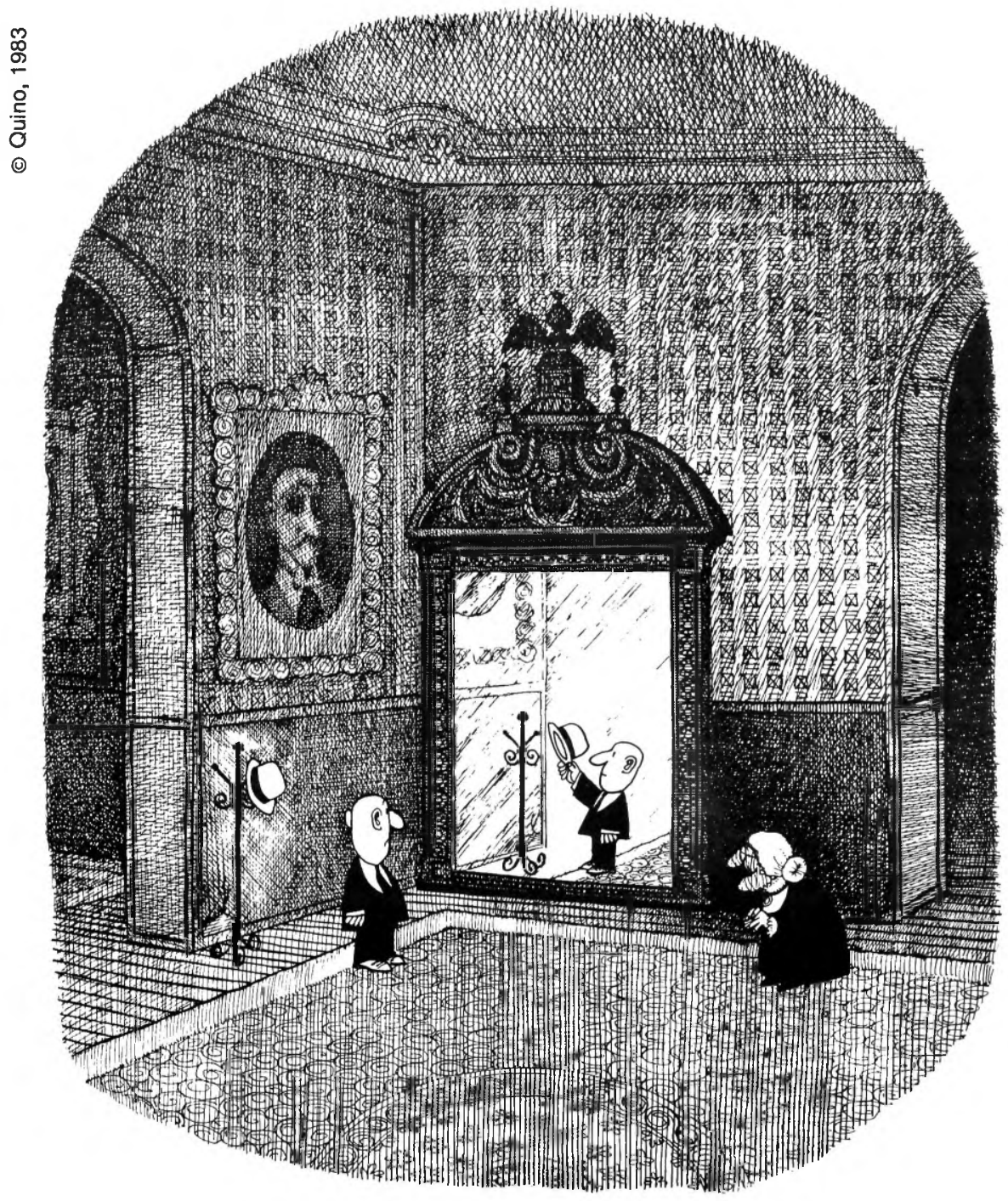

CON LOS AÑOS QUE TIENE,ES LOGICO QUE ATRASE UN POQUITIN

FOTO 5 